\section{REFERENCES}

1. Uttley AHC, Collins $\mathrm{CH}$, Naidoo J, George RC. Vancomycin-resistant enterococci. Lancet 1988;1:57-58.

2. Karanfil LV, Murphy M, Josephson A, Gaynes R, Mandel L, Hill BC, et al. A cluster of vancomycin-resistant Enterococcus faecium in an intensive care unit. Infect Control Hosp Epidemiol 1992;13:195-200.

3. Livornese LU Jr, Dias S, Samel C, Romanowski B, Taylor S, May P, et al. Hospital-acquired infection with vancomycin-resistant Enterococcus faecium transmitted by electronic thermometers. Ann Intern Med 1992;117:112-116.

4. Rubin LG, Tucci V, Cercenado E, Eliopoulos G, Isenberg HD. Vancomycin-resistant Enterococcus faecium in hospitalized children. Infect Control Hosp Epidemiol 1992;13:700-705

5. Handwerger S, Raucher B, Altarac D, Monka J, Marchione S, Singh KV, et al. Nosocomial outbreak due to Enterococcus faecium highly resistant to vancomycin, penicillin, and gentamicin. Clin Infect Dis 1993;16:750755.

6. Boyce JM, Opal SM, Chow JW, Zervos MJ, Potter-Bynoe G, Sherman $\mathrm{CB}$, et al. Outbreak of multidrug-resistant Enterococcus faecium with transferable van $\mathrm{B}$ class vancomycin resistance. I Clin Microbiol 1994;32:1148-1153.

7. Morris JG Jr, Shay DK, Hebden JN, McCarter RJ Jr, Perdue BE, Jarvis W, et al. Enterococci resistant to multiple antimicrobial agents, including vancomycin. Establishment of endemicity in a university medical center. Ann Intern Med 1995;123:250-259.

8. Uttley AH, George RC, Naidoo J, Woodford N, Johnson AP, Collins CH, et al. High-level vancomycin-resistant enterococci causing hospital infections. Epidemiol Infect 1989;103:173-181.

9. Jordens JZ, Bates J, Griffiths DJ. Fecal carriage and nosocomial spread of vancomycin-resistant Enterococcus faecium. I Antimicrob Chemother 1994;34:515-528.

10. Chadwick PR, Oppenheim BA, Fox A, Woodford N, Morgenstern GR, Scarffe JH. Epidemiology of an outbreak due to glycopeptide-resistant Enterococcus faecium on a leukaemia unit. J Hosp Infect 1996;34:171-182.

11. Brown AR, Amyes SG, Paton R, Plant WD, Stevenson GM, Winney RJ, et al. Epidemiology and control of vancomycin-resistant enterococci (VRE) in a renal unit. J Hosp Infect 1998;40:115-124.

12. Centers for Disease Control and Prevention. Nosocomial enterococci resistant to vancomycin-United States, 1989-1993. MMWR 1993;42:597599.

13. Bonten MJ, Hayden MK, Nathan C, Van Voorhis J, Matushek M, Slaughter $S$, et al. Epidemiology of colonisation of patients and environment with vancomycin-resistant enterococci. Lancet 1996;348:1615-1619.
14. Noskin GA, Stosor V, Cooper I, Peterson LR. Recovery of vancomycinresistant enterococci on fingertips and environmental surfaces. Infect Control Hosp Epidemiol 1995;16:577-581.

15. Bonilla HF, Zervos MJ, Kauffman CA. Long-term survival of vancomycin-resistant Enterococcus faecium on a contaminated surface. Infect Control Hosp Epidemiol 1996;17:770-771.

16. Falk PS, Winnike J, Woodmansee C, Desai M, Mayhall CG. Outbreak of vancomycin-resistant enterococci in a burn unit. Infect Control and Hosp Epidemiol 2000;21:575-582.

17. Hospital Infection Control Practices Advisory Committee. Recommendations for preventing the spread of vancomycin resistance. Infect Control Hosp Esidemiol 1995;16:105-113.

18. Weinstein JW, Tallapragada S, Farrel P, Dembry LM. Comparison of rectal and perirectal swabs for detection of colonization with vancomycin resistant enterococci. J Clin Microbiol 1996;34:210-212.

19. Taylor ME, Oppenheim BA, Chadwick PR, Weston D, Palepou MF, Woodford $\mathrm{N}$, et al. Detection of glycopeptide resistant enterococci in routine diagnostic faeces specimens. I Hosp Infect 1999;43:25-32.

20. Ieven M, Vercauteren E, Descheemaeker P, Van Laer F, Goossens H Comparison of direct plating and broth enrichment culture for the detec tion of intestinal colonization by glycopeptide-resistant enterococci among hospitalized patients. J Clin Microbiol 1999;37:1436-1440.

21. Landman D, Quale JM, Oydna E, Willey B, Ditore V, Zaman M, et al. Comparison of five selective media for identifying fecal carriage of vancomycin-resistant enterococci. J Clin Microbiol 1996;34:751-752.

22. Ford M, Perry JD, Gould FK, Orr KE. Neomycin blood agar as a selective medium for vancomycin-resistant Enterococcus faecium. I Clin Pathol 1996:49:437.

23. Edberg SC, Hardalo CJ, Kontnick C, Campbell S. Rapid detection of vancomycin-resistant enterococci. I Clin Microbiol 1994;32:2182-2184.

24. Ford M, Perry JD, Gould FK. Use of cephalexin-aztreonam-arabinose agar for selective isolation of Enterococcus faecium. J Clin Microbiol 1994;32:2999-3001.

25. Chadwick PR, Oppenheim BA. Neomycin blood agar as a selective medium for vancomycin resistant Enterococcus faecium. J Clin Pathol 1995;48:1068-1070.

26. Rao GG, Ghanekar K, Ojo F. Selective medium for screening for vancomycin-resistant enterococci in faeces. Eur J Clin Microbiol Infect Dis 1996;15:175-177.

27. Barton AL, Doern GV. Selective media for detecting gastrointestinal carriage of vancomycin-resistant enterococci. Diagn Microbiol Infect Dis 1995;23:119-122.

28. Van Horn KG, Gedris CA, Rodney KM. Selective isolation of vancomycin-resistant enterococci. J Clin Microbiol 1996;34:924-927.

\title{
Preventing Spread of VRE in Long-Term-Care Facility
}

\section{Gina Pugliese, RN, MS Martin S. Favero, PhD}

Silverblatt and coinvestigators from the Department of Veterans Affairs Medical Center, Providence, Rhode Island, conducted a study to test the hypothesis that infection control practices can prevent the spread of vancomycin-resistant enterococci (VRE) to residents of a longterm-care facility (LTCF) from an affiliated acute-care facility with a high endemic rate of colonization. A point-prevalence study of the rate of rectal colonization was conducted in a state-supported veterans nursing home and an acute-care veterans hospital. The participants were residents in a state veterans home. Patients with rectal colonization by VRE were identified before transfer to the state veterans home. To eliminate colonization, Contact Isolation, as well as the use of oral bacitracin, was practiced for colonized veterans. Rectal swabs and cultures for VRE were performed and clinical records reviewed, and recording of presumptive risk factors for VRE colonization was noted. The risk factors were age, gender, length of stay at nursing home, treatment with vancomycin or oral antibiotics, hospitalization at the acute-care facility during the previous year, use of indwelling urethral catheters, presence of diarrhea, and fecal or urinary incontinence.

Cultures were taken for 69 of 200 res idents in the first study (1996) and for 130 of 230 residents in the second study (1998). Residents who consented to culture differed from those who did not only with regards to gender ( 2 vs $7, P=.012$ ). In neither study were any residents found to be colonized with VRE who had not already been identified as positive on admission.

The authors concluded that adherence to infection control practices by the patient-care staff of the LTCF was associated with the absence of transmission of VRE colonization among its residents. The presence of rectal colonization with VRE in an acute-care patient should not be a barrier to acceptance in an LTCF.

FROM: Silverblatt FJ, Tibert $C$ Mikolich D, Blazek-D'Arezzo J, Alves J, Tack $M$, et al. Preventing the spread of vancomycin-resistant enterococci in a long-term care facility. Am Geriatr Soc 2000;48:1211-1215. 